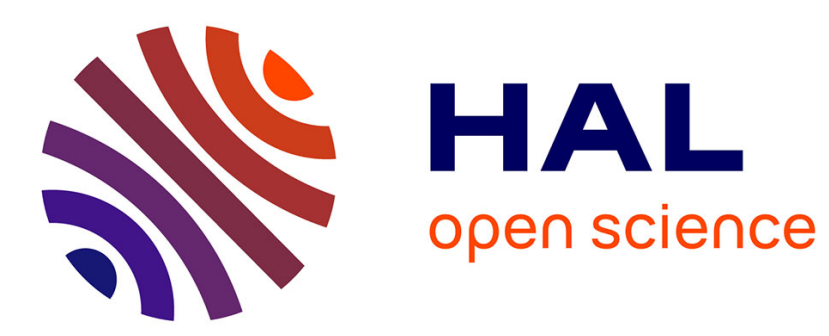

\title{
Cyclic nucleotide phosphodiesterases in heart and vessels: A therapeutic perspective
}

Pierre Bobin, Milia Belacel-Ouari, Ibrahim Bedioune, Liang Zhang, Jérôme Leroy, Véronique Leblais, Rodolphe Fischmeister, Grégoire Vandecasteele

\section{- To cite this version:}

Pierre Bobin, Milia Belacel-Ouari, Ibrahim Bedioune, Liang Zhang, Jérôme Leroy, et al.. Cyclic nucleotide phosphodiesterases in heart and vessels: A therapeutic perspective. Archives of cardiovascular diseases, 2016, 109 (6-7), pp.431-443. 10.1016/j.acvd.2016.02.004 . hal-02482730

\author{
HAL Id: hal-02482730 \\ https://hal.science/hal-02482730
}

Submitted on 23 Mar 2020

HAL is a multi-disciplinary open access archive for the deposit and dissemination of scientific research documents, whether they are published or not. The documents may come from teaching and research institutions in France or abroad, or from public or private research centers.
L'archive ouverte pluridisciplinaire HAL, est destinée au dépôt et à la diffusion de documents scientifiques de niveau recherche, publiés ou non, émanant des établissements d'enseignement et de recherche français ou étrangers, des laboratoires publics ou privés. 


\section{Cyclic nucleotide phosphodiesterases in heart and vessels: A therapeutic perspective}

Abbreviated title: Cyclic nucleotide phosphodiesterases in heart and vessels

French title: Phosphodiestérases des nucléotides cycliques dans le cœur et les vaisseaux : une perspective thérapeutique.

Pierre Bobin, Milia Belacel-Ouari, Ibrahim Bedioune, Liang Zhang, Jérôme Leroy, Véronique Leblais, Rodolphe Fischmeister*, Grégoire Vandecasteele*

UMR-S 1180, INSERM, Université Paris-Sud, Université Paris-Saclay, Châtenay-Malabry, France

* Corresponding authors. UMR-S1180, Faculté de Pharmacie, Université Paris-Sud, 5 rue J.-B. Clément, F-92296 Châtenay-Malabry Cedex, France. Tel: +33146835717 (G.

Vandecasteele); +33146835771 (R. Fischmeister). Fax: +33146835475.

E-mail addresses: gregoire.vandecasteele@u-psud.fr (G. Vandecasteele);

rodolphe.fischmeister@inserm.fr (R. Fischmeister).

P. Bobin and M. Belacel-Ouari were equal contributors.

Sources of funding: This work was supported by the Fondation de France (G. V.) and the Agence Nationale de la Recherche 2010 BLAN 1139-01 (G. V.). P. B. is supported by PhD fellowships from the lle-de-France region (CORDDIM) and the Fondation pour la Recherche Médicale. I. B. is supported by a PhD fellowship from CORDDIM. M. B.-O. is supported by PhD fellowships from the French Ministry of Research and the GRRC/French Society of Cardiology. L. Z. is supported by a PhD fellowship from the China Scholarship Council. 
Word count: 9596 


\section{Summary}

Cyclic nucleotide phosphodiesterases (PDEs) degrade the second messengers cyclic adenosine monophosphate (cAMP) and cyclic guanosine monophosphate (cGMP), thereby regulating multiple aspects of cardiac and vascular muscle function. This highly diverse class of enzymes encoded by 21 genes encompasses 11 families that are not only responsible for the termination of cyclic nucleotide signalling, but are also involved in the generation of dynamic microdomains of cAMP and cGMP, controlling specific cell functions in response to various neurohormonal stimuli. In the myocardium and vascular smooth muscle, the PDE3 and PDE4 families predominate, degrading cAMP and thereby regulating cardiac excitation-contraction coupling and smooth muscle contractile tone. PDE3 inhibitors are positive inotropes and vasodilators in humans, but their use is limited to acute heart failure and intermittent claudication. PDE5 is particularly important for the degradation of cGMP in vascular smooth muscle, and PDE5 inhibitors are used to treat erectile dysfunction and pulmonary hypertension. There is experimental evidence that these PDEs, as well as other PDE families, including PDE1, PDE2 and PDE9, may play important roles in cardiac diseases, such as hypertrophy and heart failure, as well as several vascular diseases. After a brief presentation of the cyclic nucleotide pathways in cardiac and vascular cells, and the major characteristics of the PDE superfamily, this review will focus on the current use of PDE inhibitors in cardiovascular diseases, and the recent research developments that could lead to better exploitation of the therapeutic potential of these enzymes in the future.

\section{Résumé}

Les phosphodiestérases des nucléotides cycliques (PDE) dégradent les seconds messagers AMPc et GMPc, régulant ainsi de multiples aspects des fonctions cardiaque et vasculaire. Cette classe d'enzymes très diversifiée, codée par vingt et un gènes, englobe onze familles responsables de la terminaison des signaux transmis par les nucléotides cycliques, et sont impliqués dans la génération de microdomaines dynamiques d'AMPc et de GMPc contrôlant des fonctions spécifiques des cellules en réponse à divers stimuli neuro-hormonaux. Dans le myocarde et le muscle lisse vasculaire, les PDE3 et PDE4 sont prédominantes pour dégrader 
I'AMPc et régulent le couplage excitation-contraction cardiaque et le tonus contractile des muscles lisses. Les inhibiteurs de PDE3 sont inotropes positifs et vasodilatateurs chez l'homme, mais leur utilisation est limitée au traitement de l'insuffisance cardiaque aiguë et de la claudication intermittente. La PDE5 est importante pour dégrader le GMPc dans le muscle lisse vasculaire, et les inhibiteurs de PDE5 sont utilisés pour traiter la dysfonction érectile et I'hypertension pulmonaire. Des travaux expérimentaux suggèrent que ces PDE ainsi que d'autres familles de PDE, en particulier PDE1, PDE2 et PDE9 jouent également un rôle important dans l'hypertrophie et l'insuffisance cardiaque ainsi que dans plusieurs maladies vasculaires. Après avoir donné un bref aperçu des voies des nucléotides cycliques dans les cellules cardiaques et vasculaires et des principales caractéristiques des PDEs, cette revue présentera les utilisations actuelles des inhibiteurs de PDE dans les maladies cardiovasculaires et les progrès de recherche récents susceptibles de conduire à une meilleure exploitation du potentiel thérapeutique de ces enzymes dans le futur.

\section{KEYWORDS}

CAMP;

cGMP;

Cyclic nucleotide phosphodiesterases;

Cardiovascular diseases

\section{MOTS CLÉS}

AMPc ;

GMPc ;

Phosphodiestérase des nucléotides cycliques ;

Maladies cardiovasculaires

Abbreviations: AKAP, A-kinase anchoring protein; $\beta$-AR, $\beta$-adrenergic receptor; $\mathrm{Ca}^{2+}$ : calcium; CaMKII, $\mathrm{Ca}^{2+} /$ calmodulin-dependent kinase II; cAMP, cyclic adenosine monophosphate; cGMP, cyclic guanosine monophosphate; Epac, exchange protein directly 
activated by cAMP; ERK, extracellular signal-regulated kinase; GC, guanylate cyclase; Gs:

heterotrimeric G-protein activating adenylyl cyclase; HF, heart failure; KO: knock out; LTCC, Ltype $\mathrm{Ca}^{2+}$ channel; $\mathrm{NO}$, nitric oxide; PAH, pulmonary arterial hypertension; PDE,

phosphodiesterase; PLB, phospholamban; PKA, cAMP-dependent protein kinase; PKG, cGMPdependent protein kinase; RyR2, ryanodine receptor; SERCA, sarco-endoplasmic reticulum $\mathrm{Ca}^{2+-}$ adenosine triphosphatase; SMC, smooth muscle cell; VEGF, vascular endothelial growth factor; VSMC, vascular smooth muscle cell. 


\section{Background}

The cyclic nucleotides cyclic adenosine monophosphate (cAMP) and cyclic guanosine monophosphate (cGMP) participate in the main pathways regulating cardiac and vascular function; they act as second messengers for sympathetic and parasympathetic systems, nitric oxide (NO) and natriuretic peptides. Cyclic nucleotides may exert beneficial or deleterious effects on the heart and vessels, depending on the strength and duration of the stimulation. Acute elevation of cyclic nucleotides regulates cardiac excitation-contraction coupling and vascular contractile tone. However, chronic elevation of cAMP contributes to the development of cardiac hypertrophy and progression to heart failure (HF), while cGMP possesses antihypertrophic properties. In vessels, cAMP and cGMP exert antiproliferative and antimigratory properties, therefore limiting atherosclerosis and angiogenesis. These second messengers also regulate endothelial barrier function, the disruption of which is associated with several pathological conditions, such as oedema and sepsis. The amplitude, duration and localization of cyclic nucleotide responses are determined by the balance between synthesis of cAMP and cGMP by adenylyl and guanylyl cyclases, respectively, and degradation by cyclic nucleotide phosphodiesterases (PDEs).

PDEs represent the main route to the rapid lowering of cyclic nucleotide concentrations inside the cells, and constitute a highly diverse superfamily of enzymes. The different enzymatic properties and localization patterns of the multiple PDE isoforms within the cell play a role in cyclic nucleotide compartmentation, which is critical for determining specific physiological responses [1, 2]. In addition, modification of the expression and activity of specific PDEs is observed in several cardiovascular diseases. Thus, the members of the PDE superfamily are well placed to be targets for pharmacological interventions in cardiovascular diseases; indeed, some PDE inhibitors have already been approved for the treatment of acute heart failure, erectile dysfunction, pulmonary hypertension and intermittent claudication.

In the following review, we present an overview of the roles of PDEs in cardiac and vascular muscles, the current indications for PDE inhibitors in cardiovascular diseases and recent research advances, which hold promise for future therapeutic developments in cardiovascular diseases. 


\section{Regulation of cardiac and vascular cells by cyclic nucleotide pathways}

In cardiac and vascular cells, cAMP is produced mainly by transmembrane adenylyl cyclases in response to catecholamines and various hormones or circulating factors acting on seven transmembrane receptors coupled to heterotrimeric $G$ protein stimulating adenylyl cyclase $\left(G_{s}\right)$. Two types of guanylate cyclase (GC) produce cGMP: the soluble GC that is activated by NO; and particulate GCs, which constitute the receptors for natriuretic peptides (atrial natriuretic peptide, brain natriuretic peptide and C-type natriuretic peptide). Once synthesized, cyclic nucleotides exert their effects by acting through a number of cellular effectors, including cAMPor cGMP-activated protein kinases (protein kinase A [PKA] or protein kinase G [PKG], respectively), cyclic nucleotide-gated ion channels and cAMP-activated guanine nucleotide exchange proteins (Epacs).

During the fight or flight response, epinephrine and norepinephrine bind to $\beta$-adrenoceptors ( $\beta$-ARs) in cardiomyocytes, leading to cAMP elevation and PKA activation. PKA phosphorylation of sarcolemmal L-type calcium ( $\mathrm{Ca}^{2+}$ ) channels (LTCCs), ryanodine receptors (RyR2s), phospholamban (PLB, which controls the activity of the sarco-endoplasmic reticulum $\mathrm{Ca}^{2+-}$ adenosine triphosphatase [ $\mathrm{Ca}^{2+}-$ ATPase], SERCA2) and troponin I enhances the amplitude and kinetics of $\mathrm{Ca}^{2+}$ transients in cardiomyocytes (Fig. 1), underlying the classical positive inotropic and lusitropic effects of acute sympathetic stimulation. However, sustained stimulation of $\beta$-ARs, as occurs during hypertension or in chronic heart diseases, is detrimental to the heart, as it favours maladaptive hypertrophic remodelling, apoptosis and arrhythmias. Along with PKA, Epac is activated by cAMP, and may play an important role in this context. Epac activation triggers a signalling pathway involving the phosphatase calcineurin and $\mathrm{Ca}^{2+} /$ calmodulindependent kinase II (CaMKII), stimulating hypertrophic growth [3]. CaMKII activation, which can also result from PKA-dependent increases in $\mathrm{Ca}^{2+}$, also phosphorylates RyR2, and promotes a proarrhythmogenic sarcoplasmic reticulum $\mathrm{Ca}^{2+}$ leak, which may ultimately lead to chamber dilatation and HF [4] (Fig. 1).

In the heart, cGMP is often viewed as the mirror of cAMP, opposing its effects on cardiac function. Indeed, cGMP can exert negative inotropic effects via PKG-mediated inhibition of the 
L-type $\mathrm{Ca}^{2+}$ current $[5,6]$ and phosphorylation of troponin I, to decrease myofilament sensitivity to $\mathrm{Ca}^{2+}[7]$. In addition, cGMP can modulate cAMP concentrations through regulation of distinct PDEs (see below). One proposed mechanism by which cGMP-PKG signalling exerts its antihypertrophic action is by inhibiting the calcineurin pathway [8] (Fig. 1).

Cyclic nucleotides are also critical in vessels. Both cAMP-elevating factors, such as prostacyclin I2 and catecholamines through $\beta$-AR stimulation, and cGMP-elevating factors, such as NO and natriuretic peptides, relax contractile vascular smooth muscle cells (VSMCs) and inhibit the proliferation and migration of synthetic VSMCs (Fig. 2). In addition, CAMP and cGMP control endothelial cell permeability and ability to release vasoactive agents such as NO, prostacyclin I2 or C-type natriuretic peptide [9]. Most of the effects of cAMP and cGMP appear to be mediated by the activation of PKA or PKG, leading to phosphorylation of several key proteins controlling the different vascular functions, although increasing evidence suggests a role for Epac in the regulation of endothelial barrier function and VSMC migration by CAMP [9, $10]$

\section{Overview of the PDE superfamily}

Eleven PDE families, which differ in their primary structure, catalytic properties, affinities for CAMP and/or cGMP and mechanisms of regulation, are known in mammals. Most PDE families are encoded by several genes, which together generate close to 100 different PDE isoforms by the use of different translation initiation sites and alternative splicing of messenger ribonucleic acid (mRNA). Specific isoforms are designated according to a common nomenclature: PDE is followed by a family number (1-11), a capital letter indicating the gene $(A, B, C$ or $D)$ and a final number corresponding to the splice variant. Some PDE families selectively hydrolyze cAMP (PDE4, PDE7 and PDE8), while others are specific for cGMP (PDE5, PDE6 and PDE9). A third category, the so-called dual PDEs, hydrolyze both cAMP and cGMP (PDE1, PDE2, PDE3, PDE10 and PDE11).

PDEs share a conserved catalytic domain (C-domain), showing approximately $25-52 \%$ amino acid sequence identity, but differ markedly in their regulatory $\mathrm{N}$-domains. $\mathrm{N}$-domains contain diverse elements involved in enzyme dimerization, binding of regulatory small 
molecules, phosphorylation and localization; they are characteristic to each family and their variants. For instance, the unique distinguishing feature of the PDE1 family is the existence of two binding sites for the $\mathrm{Ca}^{2+-b i n d i n g ~ p r o t e i n ~ c a l m o d u l i n ~ i n ~ t h e ~} \mathrm{~N}$-domain, which are responsible for enzyme stimulation by $\mathrm{Ca}^{2+}$. Other important domains found in several PDE families (PDE2, PDE5, PDE6, PDE10 and PDE11) are the so-called GAF domains (this acronym is based on the first letters of the three proteins in which they were first identified: G for cGMP-stimulated phosphodiesterases; A for Anabaena adenylyl cycles; F for Fhla transcription factor), which are involved in enzyme dimerization and allosteric regulation by cyclic nucleotides. In particular, for PDE2 and PDE5, cGMP-binding to their respective GAF domains stimulates enzymatic activity $[11,12]$. In contrast to PDE2, PDE3 is inhibited by cGMP, by direct competition at the catalytic site. The N-domains of various PDEs contain phosphorylation sites for distinct kinases that modulate enzymatic activity. For instance, long isoforms of PDE4 are phosphorylated by PKA, leading to an increase in CAMP hydrolytic activity [13], whereas PKG phosphorylation of PDE5 increases cGMP hydrolytic activity [14]. Long isoforms of PDE4D have been widely studied in this respect, and were shown to be phosphorylated by many other kinases, particularly the extracellular signal-regulated kinases ERK2 and ERK5, and CaMKII [15, 16]. N-domains are also important for intracellular localization, through specific regions that provide membrane association or protein-protein interaction. PDEs can associate with multiple protein partners, including scaffold proteins such as A-kinase anchoring proteins (AKAPs) or $\beta$-arrestin strategically located within the cells. More detailed descriptions of PDEs, including their structure, regulation, physiological roles and pharmacology, are available in several recent reviews $[14,17-19]$.

\section{PDEs as therapeutic targets in cardiovascular diseases}

\section{Heart failure}

In the 1970s and 1980s, PDE3 inhibitors were discovered to exhibit cardiotonic, inotropic, bronchodilatory and vasodilatory activities in several species, and were initially developed as cardiotonic agents to replace or add to cardiac glycosides in the treatment of HF [20]. However, despite beneficial haemodynamic effects in the short term, chronic use of PDE3 inhibitors was 
associated with increased cardiac arrhythmias and sudden death [21]. Thus, the use of PDE3 inhibitors is now limited to acute decompensated HF. Nevertheless, PDE3 inhibitors are targeting several functionally distinct isoforms that are co-expressed in the heart, raising the hope that more selective targeting might provide some benefits.

PDE3 is encoded by two genes, $P D E 3 A$ and $P D E 3 B$. Evidence from global $P D E 3 A$ and PDE3B knockout $(\mathrm{KO})$ mice indicate that PDE3A, but not PDE3B, is responsible for the inotropic and chronotropic effects of PDE3 inhibitors [22]. Three isoforms of PDE3A are expressed in cardiomyocytes, which differ only in their $\mathrm{N}$-terminal domain, giving rise to different intracellular localization [23]. In mice and humans, PDE3A1 controls PLB-SERCA2 activity and $\mathrm{Ca}^{2+}$ reuptake in the sarcoplasmic reticulum [24, 25] (Fig. 1). Because dephosphorylated PLB and depressed SERCA2 activity are a hallmark of HF, PDE3 inhibitors specifically targeting the PDE3A1 associated with PLB-SERCA2 may improve contractile performance and provide therapy for HF [26]. However, currently available PDE3 inhibitors have little selectivity for PDE3A versus PDE3B isoforms, which have similar catalytic domains, and no selectivity for individual PDE3A isoforms, which have identical catalytic domains. Phosphorylation of PDE3A1 was recently shown to regulate its interaction with SERCA2 [25]. Targeting this mechanism may offer an alternative to selectively enhance contractility without the harmful effects of global inhibition of PDE3 activity.

The second major PDE involved in cAMP hydrolysis in the heart is the cAMP-specific PDE4. The PDE4 family is encoded by four genes $(P D E 4 A-D)$. Most of our knowledge of the roles of individual PDE4 subtypes in the heart is limited to PDE4D. KO of the PDE4D gene in mice leads to PKA hyperphosphorylation of RyR2, increased sensitivity to exercise-induced arrhythmias and late-onset dilated cardiomyopathy [27]. PDE4D isoforms are localized in multiple compartments of the cardiomyocyte. For instance, PDE4D3 is localized at the perinuclear region, where it is part of a macromolecular complex organized by the scaffold protein muscle AKAP and comprising Epac1 and the kinase ERK5 to regulate cardiomyocyte hypertrophy [28]. This isoform is also present at the sarcolemma, where it associates through another AKAP with slowly activating delayed rectifier potassium channels controlling cardiac repolarization [29], and at myofilaments, in association with another scaffold protein, 
myomegaline [30]. In addition, distinct PDE4D isoforms have been shown to interact with $\beta_{1-}$ ARs and $\beta_{2}$-ARs, either directly or indirectly through $\beta$-arrestin, and to shape specific physiological or pathophysiological responses [31-35]. Finally, similarly to PDE3A, PDE4D also associates with the PLB/SERCA2 complex and regulates SERCA pump activity in the mouse heart [36] (Fig. 1).

A role for PDE4B in the heart emerged recently when it was identified as an integral component of the LTCC complex, and the main PDE regulating the LTCC current during $\beta-A R$ stimulation (Fig. 1). PDE4B KO mice, like PDE4D KO mice, have an increased susceptibility to ventricular arrhythmias during catecholamine stimulation, which may be the result of enhanced $\mathrm{Ca}^{2+}$ influx through the LTCC [37]. Although RyR2 phosphorylation by PKA did not seem to be affected in adult hearts from $P D E 4 B$ KO mice [37], a recent study indicates that it was increased in neonatal myocytes lacking PDE4B [38] suggesting that altered RyR2 regulation may also contribute to this arrhythmic phenotype.

As stated above, phosphorylation of certain PDE3 and PDE4 isoforms by PKA activates these enzymes, and this constitutes powerful negative feedback for cAMP signals in cardiomyocytes. This regulation has been shown to be facilitated by spatial proximity of PKA and PDEs assembled by the perinuclear muscle AKAP [28] or by phosphoinositide 3-kinase $y$ isoform, which, in addition to its lipid kinase function, also acts as an AKAP, facilitating the phosphorylation of PDE3B, PDE4A and PDE4B by PKA [39].

Although these studies underline the critical role of PDE4 in controlling $\beta$-AR stimulation in rodents, this family contributes less to the regulation of cardiac contractility in humans, where PDE3 predominates [40]. However, in human atrial strips, inhibition of PDE3 and also PDE4 potentiates the arrhythmogenic effect of $\beta$-AR stimulation, and PDE4 activity tends to decrease in the atria of patients with atrial fibrillation [41]. Further understanding of the role of PDE4 in humans may also be important for the proarrhythmic effect of PDE3 inhibitors, because PDE3 inhibitors, such as milrinone and enoximone, may also inhibit PDE4 in cardiac preparations [42, 43]. In cardiac hypertrophy and HF, there are profound alterations of the expression and activity of PDE3 and PDE4. In a model of pathological hypertrophy induced by pressure overload in rats, we found that the expression and activity of PDE3A, PDE4A and PDE4B were decreased, 
and that this was associated with a blunted regulation of subsarcolemmal cAMP generated by $\beta$-ARs by PDE3 and PDE4 [44]. In contrast, in a model of cardiac hypertrophy induced by angiotensin II, increased PDE4 activity was observed, accompanied by an increase in the 69kDa-PDE4A isoform and a decrease in the expression of the 52- and 76-kDa PDE4D isoforms. These results suggest that the level of expression of the isoforms of PDE3 and PDE4 is specifically regulated by the type of stimulus used to induce cardiac hypertrophy and the stage of the disease. Whereas an increase in CAMP-PDE can participate in desensitization of the $\beta$ AR pathway, a decrease could represent a compensatory mechanism to restore cAMP concentrations and inotropism. However, lower PDE also alters the degree of cAMP confinement, which could lead to illegitimate or excessive activation of certain pools of PKA or Epac, hence promoting maladaptive remodelling and rhythmic disturbances. This is supported by the results of a recent study showing that the specific PDE4D5 isoform regulates activation of hypertrophic programme by Epac1 upon stimulation of $\beta_{2}$-AR receptors [31]. In a very recent study, the local regulation of CAMP by PDEs in the vicinity of SERCA2 was compared using transgenic mice with cardiac expression of a PLB-targeted CAMP biosensor subjected to transaortic constriction [45]. In agreement with their known localization within the SERCA2 complex [22, 32], both PDE3 and PDE4 were found to regulate cAMP in this microdomain. Interestingly, during hypertrophy and early HF, there was a specific rearrangement of PDEs regulating this specific CAMP pool, with a decreased contribution from PDE4 and an increased contribution from PDE2 [45]. These results indicate that PDE alterations in cardiac disease include redistribution of PDE variants in discrete microcompartments of cardiomyocytes.

PDE3 and PDE4 also provide the major cAMP-degrading activities in VSMCs [46] (Fig. 2), and their expression is also modified in the aorta of rats with HF [47]. Importantly, endothelial dysfunction in HF leads to activation of PDE3 in VSMCs because of the loss of endothelial NO production and, consequently, of PDE3 inhibition by cGMP. This leads to a loss of relaxation induced by $\beta-A R$ and PDE4 inhibition, thus suggesting that inhibition of vascular PDE3 may constitute an attractive approach to restoring normal vasorelaxation in HF [47].

The dual specific PDE2 represents a minor part of CAMP hydrolytic activity in the normal heart, but the CAMP hydrolytic activity of this PDE is stimulated 5- to 30 -fold by CGMP, which 
was shown to inhibit cardiac LTCC in various species, including humans [48]. Subsequently, measurements with Förster resonance energy transfer-based sensors in neonatal rat cardiomyocytes showed that by decreasing the concentration of cAMP, PDE2 counteracts the effects of $\beta-A R$ stimulation downstream of $\beta_{3}-A R s$ [49]. In contrast to PDE3 and PDE4, the expression and activity of which are generally decreased in pathological hypertrophy and HF $[44,50,51]$, we found recently that PDE2 is increased in animal models as well as in human HF [52]. PDE2 inhibition partially restores $\beta$-AR responsiveness in diseased cardiomyocytes, suggesting that PDE2 enhancement in HF constitutes a protective mechanism against excessive $\beta$-AR stimulation. However, according to another recent study, PDE2 could exert a prohypertrophic effect by blunting PKA-mediated phosphorylation of nuclear factor of activated T cells (NFAT) [53]. Further studies are needed to fully understand the role of PDE2 in HF.

Similarly to PDE2, PDE1 and PDE5 have been reported to be overexpressed in pathological hypertrophy and HF [54-56]. Because PDE1 and PDE5 preferentially (PDE1A) or specifically (PDE5) degrade cGMP, their increase in HF can clearly be seen as maladaptive. Accordingly, transgenic mice with cardiac-specific overexpression of PDE5 are predisposed to adverse remodelling after myocardial infarction [56], whereas pharmacological inhibition of PDE1 [54] or PDE5 [57] reduces hypertrophy and improves cardiac pressure and volume overload. Numerous animal studies have shown that PDE5 inhibitors protect against ischaemia/reperfusion injury, doxorubicin cardiotoxicity, ischaemic and diabetic cardiomyopathy and Duchenne muscular dystrophy [58]. However, it remains controversial whether significant concentrations of PDE5 are expressed in the myocardium, raising the possibility that the beneficial effects of PDE5 inhibitors involve other mechanisms, including inhibition of PDE1 [59, 60]. In patients with systolic HF, the PDE5 inhibitor sildenafil decreased pulmonary vascular pressure and increased peak oxygen consumption and cardiac index [61]. Sildenafil also improved left ventricular diastolic function, cardiac geometry and clinical status in patients with systolic HF [62] and improved diabetic cardiomyopathy [63]. However, despite encouraging results in an initial single-centre study [64], chronic therapy with sildenafil was not associated with clinical benefit in patients with diastolic HF in a larger multicentre study [65]. Ongoing trials 
with PDE5 inhibitors include testing for gender response to tadalafil in left ventricular hypertrophy associated with diabetic cardiomyopathy (NCT01803828).

Two other PDEs were recently proposed to participate in cGMP degradation in the heart. Experiments performed in isolated cardiomyocytes from transgenic mice expressing a Förster resonance energy transfer-based cGMP biosensor have suggested that PDE3, which is classically known to degrade cAMP preferentially, may also be involved in the control of cGMP concentrations [66]. In addition, the cGMP-specific PDE9 was found to be expressed in rodent and human hearts, and to be upregulated in hypertrophy and HF [67]. PDE9 genetic ablation or pharmacological inhibition appears to protect the heart against pathological remodelling during pressure overload. Moreover, PDE9 inhibition reverses pre-established heart disease in a NO synthase activity-independent manner, whereas PDE5 inhibition requires active NO synthase, which is decreased in HF; this is because PDE9 seems to hydrolyze specifically cGMP generated by natriuretic peptides, whereas PDE5 controls cGMP generated by NO $[68,69]$. We have shown previously that PDE2 is critical for the regulation of subsarcolemmal cGMP concentrations in response to particulate GC activation in adult cardiomyocytes [68], thus raising the question of whether PDE2 and PDE9 exert redundant or distinct regulation of natriuretic peptide signalling.

\section{Ischaemia/reperfusion injury}

Manipulation of PDE activity may also prove protective in the context of ischaemia-reperfusion injury. Indeed, PDE5 inhibitors were shown to reduce infarct size in rabbits and mice; they also decreased cell death in isolated cardiomyocytes, suggesting that part of this effect is independent of vasodilation. Several mechanisms appear to be involved in these effects, including increased NO synthase expression, cGMP elevation, PKG activation and the opening of mitochondrial adenosine triphosphate-sensitive potassium channels and $\mathrm{Ca}^{2+}$-activated potassium channels [58]. PDE3 inhibitors have also been reported to reduce infarct size when applied before sustained ischaemia, thus mimicking the cardioprotection conferred by ischaemic preconditioning [70-72]. A recent study using KO mice for either PDE3A or PDE3B strongly suggested that PDE3B is the isoform mediating the cardioprotective effect of PDE3 inhibitors in 
this context. Indeed, $P D E 3 B$ KO mice, but not $P D E 3 A$ KO mice, were protected against ischaemia-reperfusion injury. This protective effect appears to involve cAMP/PKA-mediated opening of mitochondrial $\mathrm{Ca}^{2+}$-activated potassium channels and assembly of ischaemiainduced caveolin 3-enriched fractions [73]. Somehow at odds with the above-mentioned cardioprotective effect of PDE3 inhibitors, mice with cardiac-specific overexpression of PDE3A1 were protected during ischaemia-reperfusion injury. In addition to regulating SERCA2, PDE3A1 also acts as a negative regulator of cardiomyocyte apoptosis, by controlling the expression of the transcriptional repressor and proapoptotic factor, inducible cAMP early repressor (ICER) [74]. Inhibition of this mechanism in mice with cardiac-specific overexpression of PDE3A1 was associated with protection during ischaemia-reperfusion [75]. Collectively, these studies suggest that PDE3A and PDE3B may play an opposite role during ischaemia-reperfusion, which may be linked to their differential localization and the control of discrete cAMP pools in cardiomyocytes [73].

\section{Erectile dysfunction}

PDE5 is highly abundant in vascular smooth muscle, and by limiting the breakdown of cGMP, PDE5 inhibition potentiates the vasorelaxant effect of the NO/cGMP pathway initiated by endothelial NO production or exogenous NO produced by NO donors [76, 77] (Fig. 2). Thus, PDE5 inhibitors were initially proposed as potent vasodilators to treat coronary heart disease. In the mid-1980s, the Pfizer group developed sildenafil (UK-92480, a derivative of zaprinast) as an orally available PDE5 inhibitor (half maximal inhibitory concentration [IC 50 ] for PDE5 $\sim 5 \mathrm{nM}$ and $10 \times$ selectivity over other PDEs). Sildenafil turned out to be ineffective against angina, but was reported to induce enhanced penile erections in a number of volunteers participating in these trials. Thereafter, extensive research focused on this unexpected side effect.

Penile erection is dependent on the NO/cGMP pathway. Upon sexual stimulation, NO released in the corpora cavernosa by non-cholinergic/non-adrenergic neurons and endothelial cells promotes relaxation of surrounding smooth muscle cells (SMCs) by increasing intracellular cGMP concentrations. Relaxation of intracavernosal smooth muscle and dilatation of penile arteries promote the expanding of sinusoidal spaces, resulting in blood filling and penile 
erection. PDE5 is the predominant PDE in penile SMCs [78, 79]. Thus, PDE5 inhibitors enhance the erectile response by potentiating the effects of cGMP triggered by NO release [80].

In 1998, sildenafil (Viagra ${ }^{\circledR}$; Pfizer, New York City, NY, USA) received approval as the first oral treatment for erectile dysfunction in men. Three others PDE5 inhibitors (tadalafil, vardenafil and, more recently, avanafil) are now commercialized. No current evidence suggests a difference in their efficacy. However, sildenafil and vardenafil exhibit lower selectivity for PDE5 over PDE6, the retinal PDE, which might explain the visual disturbances experienced by some patients. According to their action mechanism, all PDE5 inhibitors require sexual stimulation to be effective, and their association with organic nitrates is contraindicated. Nevertheless, an increase in vascular PDE expression, especially PDE1A and PDE5A, has been observed in rat models of nitrate tolerance; PDE inhibition, with zaprinast [81, 82] and vinpocetine [83, 84], respectively, was effective in reversing this tolerance, suggesting that PDE upregulation is involved in the development of nitrate tolerance. The potential application of PDE inhibitors, especially PDE1 and PDE5 inhibitors, in limiting the development of nitrate tolerance remains to be evaluated in humans.

\section{Pulmonary hypertension}

Pulmonary arterial hypertension (PAH) is characterized by an increase in mean pulmonary arterial pressure, leading to a progressive functional decline with right HF and, eventually, death [85]. The pulmonary artery remodelling underlying this disease includes pulmonary vasoconstriction, in situ thrombosis, medial hypertrophy and intimal proliferation, leading to occlusion of the small- to mid-sized pulmonary arterioles and the formation of plexiform lesions. Endothelial dysfunction, leading to an imbalance in the production of vasodilator/antiproliferating factors in favour of vasoconstrictor/proliferating factors, appears to be one of the main pathobiological mechanisms of the disease, and is the rationale for current therapeutics. Impairment of the arterial pulmonary NO/cGMP/PDE5 pathway is supported by a decrease in NO synthase expression in endothelial cells from PAH patients [86], and upregulation of PDE5 in their VSMCs. Thus, PDE5 inhibition counteracts this deleterious process, promoting cGMP 
accumulation, resulting in inhibition of pulmonary vasoconstriction and VSMC growth and remodelling.

In the SUPER study, a 12-week treatment with the PDE5 inhibitor sildenafil showed improvements in exercise capacity, New York Heart Association functional class and pulmonary haemodynamics in patients with symptomatic PAH [87]. The improvements were largely sustained after 3 years of treatment (SUPER-2 study) [88]. Sildenafil (Revatio ${ }^{\circledR}$; Pfizer) was approved in 2005 for the long-term treatment of patients with class II and III PAH. Tadalafil (Adcirca ${ }^{\circledR}$; Eli Lilly and Company, Indianapolis, IN, USA) was also commercialized based on similar clinical benefits $[89,90]$.

Other PDE families may be critical in the pathogenesis of PAH. It has been shown that not only cGMP-PDE activity, but also cAMP-PDE activity is increased in rat pulmonary arteries isolated from a model of chronic hypoxia-induced PAH [91].

Expression of PDE1A, PDE1C and PDE3B is enhanced in pulmonary artery SMCs from both idiopathic and secondary PAH patients compared with control pulmonary artery SMCs [92, 93]. Methylxanthine derivatives, which exhibit low PDE1 selectivity, were shown to be protective in different preclinical models of PAH [93]. More recently, the selective PDE2 inhibitor BAY 607550 was shown to have beneficial effects on pulmonary vasoconstriction, remodelling and right ventricular hypertrophy in both hypoxia- and bleomycin-induced pulmonary hypertension in mice. The authors also reported that BAY $60-7550$ reduced the proliferation of isolated pulmonary artery SMCs from PAH patients [94]. Additional benefits were observed when BAY 60-7550 was given in conjunction with cAMP- or cGMP-elevating agents (the prostacyclin analogue treprostinil, sildenafil, atrial natriuretic peptide or NO donor). The dual promotion of cGMP and cAMP signalling upon PDE2 inhibition might be an attractive perspective in the treatment of $\mathrm{PAH}$.

\section{Post-angioplasty restenosis/atherosclerosis}

Intimal hyperplasia and luminal stenosis are the key characteristics of several different vascular disorders, such as atherosclerosis and post-angioplasty restenosis [95, 96]. 
To prevent restenosis after percutaneous coronary intervention, the most effective therapy is local delivery of antiproliferative reagents via drug-eluting stents, containing drugs such as sirolimus [97] and paclitaxel [98]. However, first-generation drug-eluting stents also attenuate re-endothelialization and can lead to increased in-stent thrombosis [99]; they also remain ineffective in treating vascular disorders with diffuse neointimal lesions. Thus, the development of novel therapeutic strategies is currently in high demand.

Under normal conditions, SMCs residing in the media of vessels are quiescent, with a low turnover rate and insignificant secretory activity. These SMCs are highly differentiated cells that exhibit a contractile phenotype by expressing large amounts of contractile proteins, and principally function to maintain vascular tone. However, SMCs also retain a degree of plasticity to allow phenotypic modulation. Under vascular injury, SMCs undergo profound metamorphosis, changing from a quiescent/contractile phenotype to an active/synthetic phenotype with proliferative and migratory properties [100]. Interestingly, this phenotype switch is associated with modification of PDE expression profile. Given the antiproliferative and antimigratory properties of cyclic nucleotides, PDEs appear of great interest in these vascular proliferative diseases.

The properties of PDE3 inhibition, leading to vasodilatation and inhibition of platelet aggregation and VSMC proliferation, appeared to be favourable in this context. Several clinical trials were designed to evaluate the benefits of the already approved and orally available PDE3 inhibitor, cilostazol. On a background of usual antiplatelet therapy with aspirin and clopidogrel, cilostazol was shown to be effective in attenuating post-angioplasty restenosis, especially in patients at high risk of restenosis 6 months after stent implantation (CREST trial) [101], and in patients with diabetes mellitus implanted with a drug-eluting stent (DECLARE-DIABETES trial) [102]. Cilostazol compared with aspirin also reduced the progression of carotid atherosclerosis at 2 years in patients with type 2 diabetes (DAPC trial) [103]. Despite the possible benefit of cilostazol in vascular diseases, its use is limited by tolerability, as some patients often report drug discontinuation because of headache, diarrhoea, dizziness or increased heart rate [104].

PDE1C is considered as a marker of VSMC proliferation in rodent as well as in human vessels (Fig. 2). Indeed, PDE1C expression was reported to be minor in the normal human 
aorta or saphenous vein, but readily up-regulated ex vivo in SMCs cultured from these vessels $[105,106]$ or isolated from aortic atherosclerosis lesions [107], as well as in vivo in neointimal human coronary artery lesions [106]. Ex vivo inhibition of PDE1C using antisense oligonucleotides or a PDE1 inhibitor resulted in suppression of proliferation of SMCs isolated from the normal aorta or from lesions of atherosclerosis [107]. More importantly, in vivo deficiency of PDE1C (PDE1C KO) or inhibition of PDE1 through perivascular application of IC86340 was shown to attenuate injury-induced neointimal formation in mouse carotid artery [106]. In this study, the authors identified a novel mechanism involved in the beneficial effects of PDE1C inhibition, a decrease in platelet-derived growth factor receptor $\beta$ expression, via a cAMP/PKA-dependent mechanism contributing to lysosomal-dependent receptor degradation in a low-density lipoprotein receptor-related protein 1-dependent manner. Thus PDE1C inhibition appears to offer novel therapeutic strategies in vascular hyperplasic disorders.

\section{Angiogenesis}

Cyclic nucleotide signalling pathways are considered to modulate several components of tumourigenesis, among them angiogenesis, which is a fundamental process in tumour growth and metastasis. The vascular endothelial growth factor (VEGF) pathway is well established as one of the key regulators of this process [108], and current antiangiogenic therapies rely on blocking VEGF activity. VEGF-induced angiogenesis is partly mediated by NO through endothelial NO synthase activation and the subsequent increase in endothelial cGMP concentration. In human umbilical vein endothelial cells, VEGF has been shown to increase PDE2 and PDE4 activity and decrease PDE5 activity. Treatment of these cells with a combination of PDE2 and PDE4 inhibitors increased CAMP concentrations and decreased VEGF-induced human umbilical vein endothelial cell migration, proliferation and cell cycle progression. This treatment also reduced the total capillary surface of the chicken embryo chorioallantoic membrane, used as an in vivo preclinical model of angiogenesis [109]. More recently, it was reported that a PDE4 inhibitor (intraperitoneal administration for 36 days) reduced in vivo the growth of A549 lung tumour xenografts in nude mice by attenuating proliferation and angiogenesis, evaluated by Ki67 and CD31 staining, respectively [110]. 
Overall, these preclinical data assessing the role of PDEs in the angiogenesis process strengthen the interest in PDE inhibitors in cancer therapy.

\section{Systemic hypertension}

PDE inhibitors are currently not indicated as antihypertensive drugs, despite their vasodilatory properties. Indeed, milrinone was reported to decrease arterial pressure after intravenous infusion [111], but as its chronic oral administration in HF patients was shown to increase mortality, most probably because of arrhythmias and cardiac arrest [21], its clinical use was restricted to acute and end-stage treatment of HF. Recently, Maass et al. [112] identified six missense $P D E 3 A$ mutations causing an autosomal dominant hypertension in brachydactyly type E patients. The mutated PDE3A exhibited a gain-of-function, with increased cAMP hydrolytic activity, responsible for VSMC hyperplasia and increased vascular resistance. This elegant study should boost the interest in selective PDE3 inhibitors in the treatment of hypertension, especially in association with brachydactyly.

\section{Intermittent claudication}

Cilostazol, a selective PDE3 inhibitor, was approved for intermittent claudication, a relatively common lower-extremity peripheral arterial disease, characterized by ischaemia-induced leg pain or cramping, and for which pharmacological therapy is limited. Cilostazol exerts dual inhibitory properties on PDE3 and adenosine uptake, which might explain the minimal cardiac effects compared with other PDE3 inhibitors [113]. By inhibiting platelet aggregation and promoting arterial vasodilation, cilostazol was shown to increase walking distance and to reduce the clinical symptoms of intermittent claudication [114]. However, its use is controversial because of the modest benefit-risk balance (in particular, because of the risk of side effects affecting the heart or serious bleeding), and it has been withdrawn in some countries (e.g. France).

\section{Concluding remarks}


Soon after the discovery of cAMP and cGMP by Sutherland and colleagues more than 50 years ago, an enzymatic activity that could degrade these second messengers was described [115]. Since then, the large diversity and complexity of the PDE superfamily has been unveiled, and the critical role of these enzymes in the cardiovascular system has been demonstrated. After several disappointments in the development of PDE3 and PDE4 inhibitors, because of their adverse effects (mortality and emesis, respectively), the success of PDE5 inhibitors in treating erectile dysfunction combined with an increasing understanding of PDE biology have raised new hopes that manipulating PDE activity with greater specificity is possible and should yield therapeutic benefits. However, the targeting of individual PDE isoforms located in distinct subcellular compartments to regulate local cAMP and/or cGMP concentrations and specific cell functions is challenging. Knowledge of the protein partners and the molecular mechanisms that govern this specific localization enables envisaging of the displacement of specific PDE pools by small molecules or peptides that disrupt protein-protein interactions, with potentially fewer adverse effects than the global inhibition of an entire PDE family. Recent examples of such a strategy include the disruption of PDE4 from heat shock protein 20 (HSP20) in cardiomyocytes, resulting in hyperphosphorylation of HSP20 and attenuated cardiac hypertrophic growth [116, 117], and the disruption of Epac1-PDE3B and Epac1-PDE4D complexes involved in the control of endothelial cell adhesion, spreading and permeability $[118,119]$. Another interesting strategy is the development of allosteric inhibitors of PDEs, for instance, targeting the GAF domain of PDE5 to block enzyme activation, but not its basal activity [120], or exploiting sequence differences outside the active site to reach isoform selectivity in the case of PDE4B and PDE4D $[121,122]$. The allosteric mode of regulation could also facilitate the discovery of small molecules acting as activators for specific PDEs, which may actually be useful in correcting the detrimental effects of excessive $\beta$-AR stimulation observed in HF.

\section{Disclosure of interest}

The authors declare that they have no conflicts of interest concerning this article. 


\section{References}

[1] Steinberg SF, Brunton LL. Compartmentation of G protein-coupled signaling pathways in cardiac myocytes. Annu Rev Pharmacol Toxicol 2001;41:751-73.

[2] Conti M, Mika D, Richter W. Perspectives on: Cyclic nucleotide microdomains and signaling specificity: Cyclic AMP compartments and signaling specificity: Role of cyclic nucleotide phosphodiesterases. J Gen Physiol 2014;143:29-38.

[3] Metrich M, Lucas A, Gastineau M, et al. Epac mediates beta-adrenergic receptorinduced cardiomyocyte hypertrophy. Circ Res 2008;102:959-65.

[4] Ruiz-Hurtado G, Morel E, Dominguez-Rodriguez A, et al. Epac in cardiac calcium signaling. J Mol Cell Cardiol 2012.

[5] Mery PF, Lohmann SM, Walter U, Fischmeister R. Ca2+ current is regulated by cyclic GMP-dependent protein kinase in mammalian cardiac myocytes. Proc Natl Acad Sci U S A 1991;88:1197-201.

[6] Yang L, Liu G, Zakharov SI, Bellinger AM, Mongillo M, Marx SO. Protein kinase G phosphorylates Cav1.2 alpha1c and beta2 subunits. Circ Res 2007;101:465-74.

[7] Layland J, Solaro RJ, Shah AM. Regulation of cardiac contractile function by troponin I phosphorylation. Cardiovasc Res 2005;66:12-21.

[8] Tsai EJ, Kass DA. Cyclic GMP signaling in cardiovascular pathophysiology and therapeutics. Pharmacol Ther 2009;122:216-38.

[9] Maurice DH, Tilley DG. Regulation of PDE expression in arteries: Role in controlling vascular cyclic nucleotide signaling. In: Beavo JA, Francis SH, Houslay MD, eds. Cyclic Nucleotide Phosphodiesterases in Health and Disease. Boca Raton: CRC Press; 2007:441-63.

[10] Metrich M, Berthouze M, Morel E, Crozatier B, Gomez AM, Lezoualc'h F. Role of the cAMP-binding protein Epac in cardiovascular physiology and pathophysiology. Pflugers Arch 2010;459:535-46.

[11] Martins TJ, Mumby MC, Beavo JA. Purification and characterization of a cyclic GMPstimulated cyclic nucleotide phosphodiesterase from bovine tissues. J Biol Chem 1982;257:1973-9. 
[12] Rybalkin SD, Rybalkina IG, Shimizu-Albergine M, Tang XB, Beavo JA. PDE5 is converted to an activated state upon cGMP binding to the GAF A domain. EMBO J 2003;22:469-78.

[13] Sette C, Conti M. Phosphorylation and activation of a cAMP-specific phosphodiesterase by the cAMP-dependent protein kinase. Involvement of serine 54 in the enzyme activation. J Biol Chem 1996;271:16526-34.

[14] Francis SH, Blount MA, Corbin JD. Mammalian cyclic nucleotide phosphodiesterases: molecular mechanisms and physiological functions. Physiol Rev 2011;91:651-90.

[15] Mika D, Richter W, Conti M. A CaMKII/PDE4D negative feedback regulates cAMP signaling. Proc Natl Acad Sci U S A 2015;112:2023-8.

[16] Mika D, Conti M. PDE4D phosphorylation: A coincidence detector integrating multiple signaling pathways. Cell Signal 2015.

[17] Conti M, Beavo J. Biochemistry and Physiology of Cyclic Nucleotide Phosphodiesterases: Essential Components in Cyclic Nucleotide Signaling. Annu Rev Biochem 2007;76:481-511.

[18] Keravis T, Lugnier C. Cyclic nucleotide phosphodiesterase (PDE) isozymes as targets of the intracellular signalling network: benefits of PDE inhibitors in various diseases and perspectives for future therapeutic developments. Br J Pharmacol 2012;165:1288-305.

[19] Maurice DH, Ke H, Ahmad F, Wang Y, Chung J, Manganiello VC. Advances in targeting cyclic nucleotide phosphodiesterases. Nat Rev Drug Discov 2014;13:290-314.

[20] Movsesian M, Wever-Pinzon O, Vandeput F. PDE3 inhibition in dilated cardiomyopathy. Curr Opin Pharmacol 2011;11:707-13.

[21] Amsallem E, Kasparian C, Haddour G, Boissel JP, Nony P. Phosphodiesterase III inhibitors for heart failure. Cochrane Database Syst Rev 2005:CD002230.

[22] Sun B, Li H, Shakur Y, et al. Role of phosphodiesterase type 3A and 3B in regulating platelet and cardiac function using subtype-selective knockout mice. Cell Signal 2007;19:1765-71. 
[23] Wechsler J, Choi YH, Krall J, Ahmad F, Manganiello VC, Movsesian MA. Isoforms of cyclic nucleotide phosphodiesterase PDE3A in cardiac myocytes. J Biol Chem 2002;277:38072-8.

[24] Beca S, Ahmad F, Shen W, et al. PDE3A Regulates Basal Myocardial Contractility Through Interacting with SERCA2a-Signaling Complexes in Mouse Heart. Circ Res 2013;112:289-97

[25] Ahmad F, Shen W, Vandeput F, et al. Regulation of sarcoplasmic reticulum Ca2+ ATPase 2 (SERCA2) activity by phosphodiesterase 3A (PDE3A) in human myocardium: phosphorylation-dependent interaction of PDE3A1 with SERCA2. J Biol Chem 2015;290:6763-76.

[26] Movsesian M. New pharmacologic interventions to increase cardiac contractility: challenges and opportunities. Curr Opin Cardiol 2015.

[27] Lehnart SE, Wehrens XH, Reiken S, et al. Phosphodiesterase 4D deficiency in the ryanodine-receptor complex promotes heart failure and arrhythmias. Cell 2005;123:2535.

[28] Dodge-Kafka KL, Soughayer J, Pare GC, et al. The protein kinase A anchoring protein mAKAP coordinates two integrated cAMP effector pathways. Nature 2005;437:574-8.

[29] Terrenoire C, Houslay MD, Baillie GS, Kass RS. The cardiac IKs potassium channel macromolecular complex includes the phosphodiesterase PDE4D3. J Biol Chem 2009;284:9140-6.

[30] Verde I, Pahlke G, Salanova M, et al. Myomegalin is a novel protein of the golgi/centrosome that interacts with a cyclic nucleotide phosphodiesterase. J Biol Chem $2001 ; 276: 11189-98$.

[31] Baillie GS, Sood A, McPhee I, et al. beta-Arrestin-mediated PDE4 cAMP phosphodiesterase recruitment regulates beta-adrenoceptor switching from Gs to Gi. Proc Natl Acad Sci U S A 2003;100:940-5.

[32] De Arcangelis V, Liu R, Soto D, Xiang Y. Differential association of phosphodiesterase 4D isoforms with beta2-adrenoceptor in cardiac myocytes. J Biol Chem 2009;284:33824-32. 
[33] Richter W, Day P, Agrawal R, et al. Signaling from beta1- and beta2-adrenergic receptors is defined by differential interactions with PDE4. EMBO J 2008;27:384-93.

[34] Richter W, Mika D, Blanchard E, Day P, Conti M. beta1-adrenergic receptor antagonists signal via PDE4 translocation. EMBO Rep 2013;14:276-83.

[35] Berthouze-Duquesnes M, Lucas A, Sauliere A, et al. Specific interactions between Epac1, beta-arrestin2 and PDE4D5 regulate beta-adrenergic receptor subtype differential effects on cardiac hypertrophic signaling. Cell Signal 2013;25:970-80.

[36] Beca S, Helli PB, Simpson JA, et al. Phosphodiesterase 4D regulates baseline sarcoplasmic reticulum Ca2+ release and cardiac contractility, independently of L-type Ca2+ current. Circ Res 2011;109:1024-30.

[37] Leroy J, Richter W, Mika D, et al. Phosphodiesterase 4B in the cardiac L-type Ca2+ channel complex regulates $\mathrm{Ca} 2+$ current and protects against ventricular arrhythmias in mice. J Clin Invest 2011;121:2651-61.

[38] Mika DP, Richter WP, Westenbroek REP, Catterall WAP, Conti MM. PDE4B mediates local feedback regulation of beta1-adrenergic cAMP signaling in a sarcolemmal compartment of cardiac myocytes. J Cell Sci 2014.

[39] Ghigo A, Perino A, Mehel H, et al. PI3Kgamma Protects against CatecholamineInduced Ventricular Arrhythmia through PKA-mediated Regulation of Distinct Phosphodiesterases. Circulation 2012;126:2073-83.

[40] Molenaar P, Christ T, Hussain RI, et al. PDE3, but not PDE4, reduces beta(1) - and beta(2)-adrenoceptor-mediated inotropic and lusitropic effects in failing ventricle from metoprolol-treated patients. Br J Pharmacol 2013;169:528-38.

[41] Molina CE, Leroy J, Richter W, et al. Cyclic adenosine monophosphate phosphodiesterase type 4 protects against atrial arrhythmias. J Am Coll Cardiol 2012;59:2182-90.

[42] Shakur Y, Fong M, Hensley J, et al. Comparison of the effects of cilostazol and milrinone on cAMP-PDE activity, intracellular cAMP and calcium in the heart. Cardiovasc Drugs Ther 2002;16:417-27. 
[43] Bethke T, Eschenhagen T, Klimkiewicz A, et al. Phosphodiesterase inhibition by enoximone in preparations from nonfailing and failing human hearts.

Arzneimittelforschung 1992;42:437-45.

[44] Abi-Gerges A, Richter W, Lefebvre F, et al. Decreased expression and activity of cAMP phosphodiesterases in cardiac hypertrophy and its impact on beta-adrenergic cAMP signals. Circ Res 2009;105:784-92.

[45] Sprenger JU, Perera RK, Steinbrecher JH, et al. In vivo model with targeted cAMP biosensor reveals changes in receptor-microdomain communication in cardiac disease. Nat Commun 2015;6:6965.

[46] Zhai K, Hubert F, Nicolas V, Ji G, Fischmeister R, Leblais V. beta-Adrenergic cAMP signals are predominantly regulated by phosphodiesterase type 4 in cultured adult rat aortic smooth muscle cells. PLoS One 2012;7:e47826.

[47] Hubert F, Belacel-Ouari M, Manoury B, et al. Alteration of vascular reactivity in heart failure: role of phosphodiesterases 3 and 4. Br J Pharmacol 2014;171:5361-75.

[48] Fischmeister R, Castro L, Abi-Gerges A, Rochais F, Vandecasteele G. Species- and tissue-dependent effects of NO and cyclic GMP on cardiac ion channels. Comp Biochem Physiol A Mol Integr Physiol 2005;142:136-43.

[49] Mongillo M, Tocchetti CG, Terrin A, et al. Compartmentalized Phosphodiesterase-2 Activity Blunts \{beta\}-Adrenergic Cardiac Inotropy via an NO/cGMP-Dependent Pathway. Circ Res 2005;98:226-34.

[50] Osadchii OE. Myocardial phosphodiesterases and regulation of cardiac contractility in health and cardiac disease. Cardiovasc Drugs Ther 2007;21:171-94.

[51] Ding B, Abe J, Wei H, et al. Functional role of phosphodiesterase 3 in cardiomyocyte apoptosis: implication in heart failure. Circulation 2005;111:2469-76.

[52] Mehel H, Emons J, Vettel C, et al. Phosphodiesterase-2 Is Up-Regulated in Human Failing Hearts and Blunts beta-Adrenergic Responses in Cardiomyocytes. J Am Coll Cardiol 2013;62:1596-606.

[53] Zoccarato A, Surdo NC, Aronsen JM, et al. Cardiac Hypertrophy Is Inhibited by a Local Pool of cAMP Regulated by Phosphodiesterase 2. Circ Res 2015. 
[54] Miller CL, Oikawa M, Cai Y, et al. Role of $\mathrm{Ca2+/calmodulin-stimulated} \mathrm{cyclic} \mathrm{nucleotide}$ phosphodiesterase 1 in mediating cardiomyocyte hypertrophy. Circ Res 2009;105:95664.

[55] Vandeput F, Wolda SL, Krall J, et al. Cyclic nucleotide phosphodiesterase PDE1C1 in human cardiac myocytes. J Biol Chem 2007;282:32749-57.

[56] Pokreisz P, Vandenwijngaert S, Bito V, et al. Ventricular Phosphodiesterase-5 Expression Is Increased in Patients With Advanced Heart Failure and Contributes to Adverse Ventricular Remodeling After Myocardial Infarction in Mice. Circulation 2009;119:408-16.

[57] Takimoto E, Champion HC, Li M, et al. Chronic inhibition of cyclic GMP phosphodiesterase 5A prevents and reverses cardiac hypertrophy. Nat Med 2005;11:214-22

[58] Das A, Durrant D, Salloum FN, Xi L, Kukreja RC. PDE5 inhibitors as therapeutics for heart disease, diabetes and cancer. Pharmacol Ther 2015;147:12-21.

[59] Lukowski R, Krieg T, Rybalkin SD, Beavo J, Hofmann F. Turning on cGMP-dependent pathways to treat cardiac dysfunctions: boom, bust, and beyond. Trends Pharmacol Sci 2014;35:404-13.

[60] Degen CV, Bishu K, Zakeri R, Ogut O, Redfield MM, Brozovich FV. The emperor's new clothes: PDE5 and the heart. PLoS One 2015;10:e0118664.

[61] Lewis GD, Lachmann J, Camuso J, et al. Sildenafil improves exercise hemodynamics and oxygen uptake in patients with systolic heart failure. Circulation 2007;115:59-66.

[62] Guazzi M, Vicenzi M, Arena R, Guazzi MD. PDE5 inhibition with sildenafil improves left ventricular diastolic function, cardiac geometry, and clinical status in patients with stable systolic heart failure: results of a 1-year, prospective, randomized, placebo-controlled study. Circ Heart Fail 2011;4:8-17.

[63] Giannetta E, Isidori AM, Galea N, et al. Chronic Inhibition of cGMP phosphodiesterase 5A improves diabetic cardiomyopathy: a randomized, controlled clinical trial using magnetic resonance imaging with myocardial tagging. Circulation 2012;125:2323-33. 
[64] Guazzi M, Vicenzi M, Arena R, Guazzi MD. Pulmonary hypertension in heart failure with preserved ejection fraction: a target of phosphodiesterase-5 inhibition in a 1-year study. Circulation 2011;124:164-74.

[65] Redfield MM, Chen HH, Borlaug BA, et al. Effect of phosphodiesterase-5 inhibition on exercise capacity and clinical status in heart failure with preserved ejection fraction: a randomized clinical trial. JAMA 2013;309:1268-77.

[66] Gotz KR, Sprenger JU, Perera RK, et al. Transgenic mice for real-time visualization of cGMP in intact adult cardiomyocytes. Circ Res 2014;114:1235-45.

[67] Lee DI, Zhu G, Sasaki T, et al. Phosphodiesterase 9A controls nitric-oxide-independent cGMP and hypertrophic heart disease. Nature 2015;519:472-6.

[68] Castro LR, Verde I, Cooper DM, Fischmeister R. Cyclic guanosine monophosphate compartmentation in rat cardiac myocytes. Circulation 2006;113:2221-8.

[69] Takimoto E, Belardi D, Tocchetti CG, et al. Compartmentalization of cardiac betaadrenergic inotropy modulation by phosphodiesterase type 5 . Circulation 2007;115:2159-67.

[70] Sanada S, Kitakaze M, Papst PJ, et al. Cardioprotective effect afforded by transient exposure to phosphodiesterase III inhibitors: the role of protein kinase A and p38 mitogen-activated protein kinase. Circulation 2001;104:705-10.

[71] Tosaka S, Makita T, Tosaka R, et al. Cardioprotection induced by olprinone, a phosphodiesterase III inhibitor, involves phosphatidylinositol-3-OH kinase-Akt and a mitochondrial permeability transition pore during early reperfusion. J Anesth 2007;21:176-80.

[72] Fukasawa M, Nishida H, Sato T, Miyazaki M, Nakaya H. 6-[4-(1-Cyclohexyl-1H-tetrazol5-yl)butoxy]-3,4-dihydro-2-(1H)quinolinone (cilostazol), a phosphodiesterase type 3 inhibitor, reduces infarct size via activation of mitochondrial $\mathrm{Ca} 2+$-activated $\mathrm{K}+$ channels in rabbit hearts. J Pharmacol Exp Ther 2008;326:100-4.

[73] Chung YW, Lagranha C, Chen Y, et al. Targeted disruption of PDE3B, but not PDE3A, protects murine heart from ischemia/reperfusion injury. Proc Natl Acad Sci U S A 2015;112:E2253-62. 
[74] Yan C, Miller CL, Abe J. Regulation of phosphodiesterase 3 and inducible cAMP early repressor in the heart. Circ Res 2007;100:489-501.

[75] Oikawa M, Wu M, Lim S, et al. Cyclic nucleotide phosphodiesterase 3A1 protects the heart against ischemia-reperfusion injury. J Mol Cell Cardiol 2013.

[76] Martin W, Furchgott RF, Villani GM, Jothianandan D. Phosphodiesterase inhibitors induce endothelium-dependent relaxation of rat and rabbit aorta by potentiating the effects of spontaneously released endothelium-derived relaxing factor. J Pharmacol Exp Ther 1986;237:539-47.

[77] Harris AL, Lemp BM, Bentley RG, Perrone MH, Hamel LT, Silver PJ.

Phosphodiesterase isozyme inhibition and the potentiation by zaprinast of endotheliumderived relaxing factor and guanylate cyclase stimulating agents in vascular smooth muscle. J Pharmacol Exp Ther 1989;249:394-400.

[78] Taher A, Meyer M, Stief CG, Jonas U, Forssmann WG. Cyclic nucleotide phosphodiesterase in human cavernous smooth muscle. World J Urol 1997;15:32-5.

[79] Kuthe A, Wiedenroth A, Magert HJ, et al. Expression of different phosphodiesterase genes in human cavernous smooth muscle. J Urol 2001;165:280-3.

[80] Boolell M, Gepi-Attee S, Gingell JC, Allen MJ. Sildenafil, a novel effective oral therapy for male erectile dysfunction. Br J Urol 1996;78:257-61.

[81] Pagani ED, VanAller GS, O'Connor B, Silver PJ. Reversal of nitroglycerin tolerance in vitro by the cGMP-phosphodiesterase inhibitor zaprinast. Eur J Pharmacol 1993;243:141-7.

[82] Kass DA, Champion HC, Beavo JA. Phosphodiesterase type 5: expanding roles in cardiovascular regulation. Circ Res 2007;101:1084-95.

[83] Kim D, Rybalkin SD, Pi X, et al. Upregulation of Phosphodiesterase 1A1 Expression Is Associated With the Development of Nitrate Tolerance. Circulation 2001;104:2338-43.

[84] Munzel T, Daiber A, Mulsch A. Explaining the phenomenon of nitrate tolerance. Circ Res 2005;97:618-28.

[85] McLaughlin VV, McGoon MD. Pulmonary arterial hypertension. Circulation 2006;114:1417-31. 
[86] Giaid A, Saleh D. Reduced expression of endothelial nitric oxide synthase in the lungs of patients with pulmonary hypertension. N Engl J Med 1995;333:214-21.

[87] Galie N, Ghofrani HA, Torbicki A, et al. Sildenafil citrate therapy for pulmonary arterial hypertension. N Engl J Med 2005;353:2148-57.

[88] Rubin LJ, Badesch DB, Fleming TR, et al. Long-term treatment with sildenafil citrate in pulmonary arterial hypertension: the SUPER-2 study. Chest 2011;140:1274-83.

[89] Prasad S, Wilkinson J, Gatzoulis MA. Sildenafil in primary pulmonary hypertension. N Engl J Med 2000;343:1342.

[90] Steiner MK, Preston IR, Klinger JR, Hill NS. Pulmonary hypertension: inhaled nitric oxide, sildenafil and natriuretic peptides. Curr Opin Pharmacol 2005;5:245-50.

[91] Maclean MR, Johnston ED, McCulloch KM, Pooley L, Houslay MD, Sweeney G. Phosphodiesterase isoforms in the pulmonary arterial circulation of the rat: changes in pulmonary hypertension. J Pharmacol Exp Ther 1997;283:619-24.

[92] Murray F, Patel HH, Suda RY, et al. Expression and activity of cAMP phosphodiesterase isoforms in pulmonary artery smooth muscle cells from patients with pulmonary hypertension: role for PDE1. Am J Physiol Lung Cell Mol Physiol 2007;292:L294-303.

[93] Schermuly RT, Pullamsetti SS, Kwapiszewska G, et al. Phosphodiesterase 1 upregulation in pulmonary arterial hypertension: target for reverse-remodeling therapy. Circulation 2007;115:2331-9.

[94] Bubb KJ, Trinder SL, Baliga RS, et al. Inhibition of Phosphodiesterase 2 Augments cGMP and cAMP Signaling to Ameliorate Pulmonary Hypertension. Circulation 2014;130:496-507.

[95] Ross R. The pathogenesis of atherosclerosis: a perspective for the 1990s. Nature 1993;362:801-9.

[96] Kearney M, Pieczek A, Haley L, et al. Histopathology of in-stent restenosis in patients with peripheral artery disease. Circulation 1997;95:1998-2002.

[97] Moses JW, Leon MB, Popma JJ, et al. Sirolimus-eluting stents versus standard stents in patients with stenosis in a native coronary artery. N Engl J Med 2003;349:1315-23. 
[98] Stone GW, Ellis SG, Cox DA, et al. A polymer-based, paclitaxel-eluting stent in patients with coronary artery disease. N Engl J Med 2004;350:221-31.

[99] Pendyala LK, Yin X, Li J, Chen JP, Chronos N, Hou D. The first-generation drug-eluting stents and coronary endothelial dysfunction. JACC Cardiovasc Interv 2009;2:1169-77.

[100] Owens GK, Kumar MS, Wamhoff BR. Molecular Regulation of Vascular Smooth Muscle Cell Differentiation in Development and Disease. Physiological Reviews 2004;84:767801.

[101] Douglas JS, Jr., Holmes DR, Jr., Kereiakes DJ, et al. Coronary stent restenosis in patients treated with cilostazol. Circulation 2005;112:2826-32.

[102] Lee SW, Park SW, Kim YH, et al. Drug-eluting stenting followed by cilostazol treatment reduces late restenosis in patients with diabetes mellitus the DECLARE-DIABETES Trial (A Randomized Comparison of Triple Antiplatelet Therapy with Dual Antiplatelet Therapy After Drug-Eluting Stent Implantation in Diabetic Patients). J Am Coll Cardiol 2008;51:1181-7.

[103] Katakami N, Kim YS, Kawamori R, Yamasaki Y. The phosphodiesterase inhibitor cilostazol induces regression of carotid atherosclerosis in subjects with type 2 diabetes mellitus: principal results of the Diabetic Atherosclerosis Prevention by Cilostazol (DAPC) study: a randomized trial. Circulation 2010;121:2584-91.

[104] Rogers KC, Oliphant CS, Finks SW. Clinical efficacy and safety of cilostazol: a critical review of the literature. Drugs 2015;75:377-95.

[105] Rybalkin SD, Bornfeldt KE, Sonnenburg WK, et al. Calmodulin-stimulated cyclic nucleotide phosphodiesterase (PDE1C) is induced in human arterial smooth muscle cells of the synthetic, proliferative phenotype. Journal of Clinical Investigation 1997;100:2611-21.

[106] Cai Y, Nagel DJ, Zhou Q, et al. Role of cAMP-Phosphodiesterase 1C Signaling in Regulating Growth Factor Receptor Stability, Vascular Smooth Muscle Cell Growth, Migration, and Neointimal Hyperplasia. Circulation Research 2015;116:1120-32. 
[107] Rybalkin SD, Rybalkina I, Beavo JA, Bornfeldt KE. Cyclic Nucleotide Phosphodiesterase 1C Promotes Human Arterial Smooth Muscle Cell Proliferation. Circulation Research 2002;90:151-7.

[108] Hicklin DJ, Ellis LM. Role of the vascular endothelial growth factor pathway in tumor growth and angiogenesis. J Clin Oncol 2005;23:1011-27.

[109] Favot L, Keravis T, Holl V, Le Bec A, Lugnier C. VEGF-induced HUVEC migration and proliferation are decreased by PDE2 and PDE4 inhibitors. Thromb Haemost 2003;90:334-43

[110] Pullamsetti SS, Banat GA, Schmall A, et al. Phosphodiesterase-4 promotes proliferation and angiogenesis of lung cancer by crosstalk with HIF. Oncogene 2013;32:1121-34.

[111] Grose R, Strain J, Greenberg M, LeJemtel TH. Systemic and coronary effects of intravenous milrinone and dobutamine in congestive heart failure. J Am Coll Cardiol 1986;7:1107-13.

[112] Maass PG, Aydin A, Luft FC, et al. PDE3A mutations cause autosomal dominant hypertension with brachydactyly. Nat Genet 2015;47:647-53.

[113] Kambayashi J, Shakur Y, Liu Y. Bench to bedside: multiple actions of the PDE3 inhibitor Cilostazol. In: Beavo JA, Francis SH, Houslay MD, eds. Cyclic Nucleotide Phosphodiesterases in Health and Disease. Boca Raton: Boca Raton; 2007:627-48.

[114] Money SR, Herd JA, Isaacsohn JL, et al. Effect of cilostazol on walking distances in patients with intermittent claudication caused by peripheral vascular disease. J Vasc Surg 1998;27:267-74; discussion 74-5.

[115] Sutherland EW, Rall TW. Fractionation and characterization of a cyclic adenine ribonucleotide formed by tissue particles. J Biol Chem 1958;232:1077-91.

[116] Sin YY, Edwards HV, Li X, et al. Disruption of the cyclic AMP phosphodiesterase-4 (PDE4)-HSP20 complex attenuates the beta-agonist induced hypertrophic response in cardiac myocytes. J Mol Cell Cardiol 2011;50:872-83.

[117] Martin TP, Hortigon-Vinagre MP, Findlay JE, Elliott C, Currie S, Baillie GS. Targeted disruption of the heat shock protein 20-phosphodiesterase 4D (PDE4D) interaction 
protects against pathological cardiac remodelling in a mouse model of hypertrophy. FEBS Open Bio 2014;4:923-7.

[118] Wilson LS, Baillie GS, Pritchard LM, et al. A phosphodiesterase 3B-based signaling complex integrates exchange protein activated by CAMP 1 and phosphatidylinositol 3kinase signals in human arterial endothelial cells. J Biol Chem 2011;286:16285-96.

[119] Rampersad SN, Ovens JD, Huston E, et al. Cyclic AMP phosphodiesterase 4D (PDE4D) Tethers EPAC1 in a vascular endothelial cadherin (VE-Cad)-based signaling complex and controls cAMP-mediated vascular permeability. J Biol Chem 2010;285:33614-22.

[120] Schultz JE, Dunkern T, Gawlitta-Gorka E, Sorg G. The GAF-tandem domain of phosphodiesterase 5 as a potential drug target. Handb Exp Pharmacol 2011:151-66.

[121] Burgin AB, Magnusson OT, Singh J, et al. Design of phosphodiesterase 4D (PDE4D) allosteric modulators for enhancing cognition with improved safety. Nat Biotechnol 2010;28:63-70.

[122] Fox D, 3rd, Burgin AB, Gurney ME. Structural basis for the design of selective phosphodiesterase 4B inhibitors. Cell Signal 2014;26:657-63. 


\section{Figure legends}

Figure 1. Cyclic nucleotides metabolism in cardiac myocytes. The major phosphodiesterases (PDEs) expressed in cardiac myocytes are indicated, together with their subcellular localization in relation to their role in regulating hypertrophic growth and excitation-contraction coupling. For simplicity, the PDE family and - when relevant - the gene are indicated, but not the specific splice variants. AC: adenylate cyclase; AKAP: A-kinase anchoring protein; $\beta$-AR: $\beta$-adrenergic receptor; $\mathrm{Ca}^{2+}$ : calcium; CaMKII: $\mathrm{Ca}^{2+} /$ calmodulin-dependent kinase II; cAMP: cyclic adenosine monophosphate; CaN: calcineurin; cGMP: cyclic guanosine monophosphate; Epac: exchange protein directly activated by cAMP; Gs: heterotrimeric G-protein activating adenylyl cyclase; LTCC: L-type $\mathrm{Ca}^{2+}$ channels; NO: nitric oxide; pGC: particulate guanylate cyclase; PKA: cAMPdependent protein kinase; PKG: cGMP-dependent protein kinase; PLB: phospholamban; RyR: ryanodine receptor; SERCA: sarco-endoplasmic reticulum $\mathrm{Ca}^{2+}$-adenosine triphosphatase; sGC: soluble guanylate cyclase.

Figure 2. Cyclic nucleotide metabolism in vascular endothelial and smooth muscle cells. For each cell type, the main pathways leading to cyclic adenosine monophosphate (cAMP) and cyclic guanosine monophosphate (cGMP) synthesis as well as the major phosphodiesterase (PDE) families involved in their degradation are indicated. AC: adenylate cyclase; GPCR: Gprotein coupled receptor; Gs: heterotrimeric G-protein activating adenylyl cyclase; NO: nitric oxide; NOS: NO synthase; pGC: particulate guanylate cyclase; PGI2: prostacyclin I2; sGC: soluble guanylate cyclase; VEGF: vascular endothelial growth factor. 


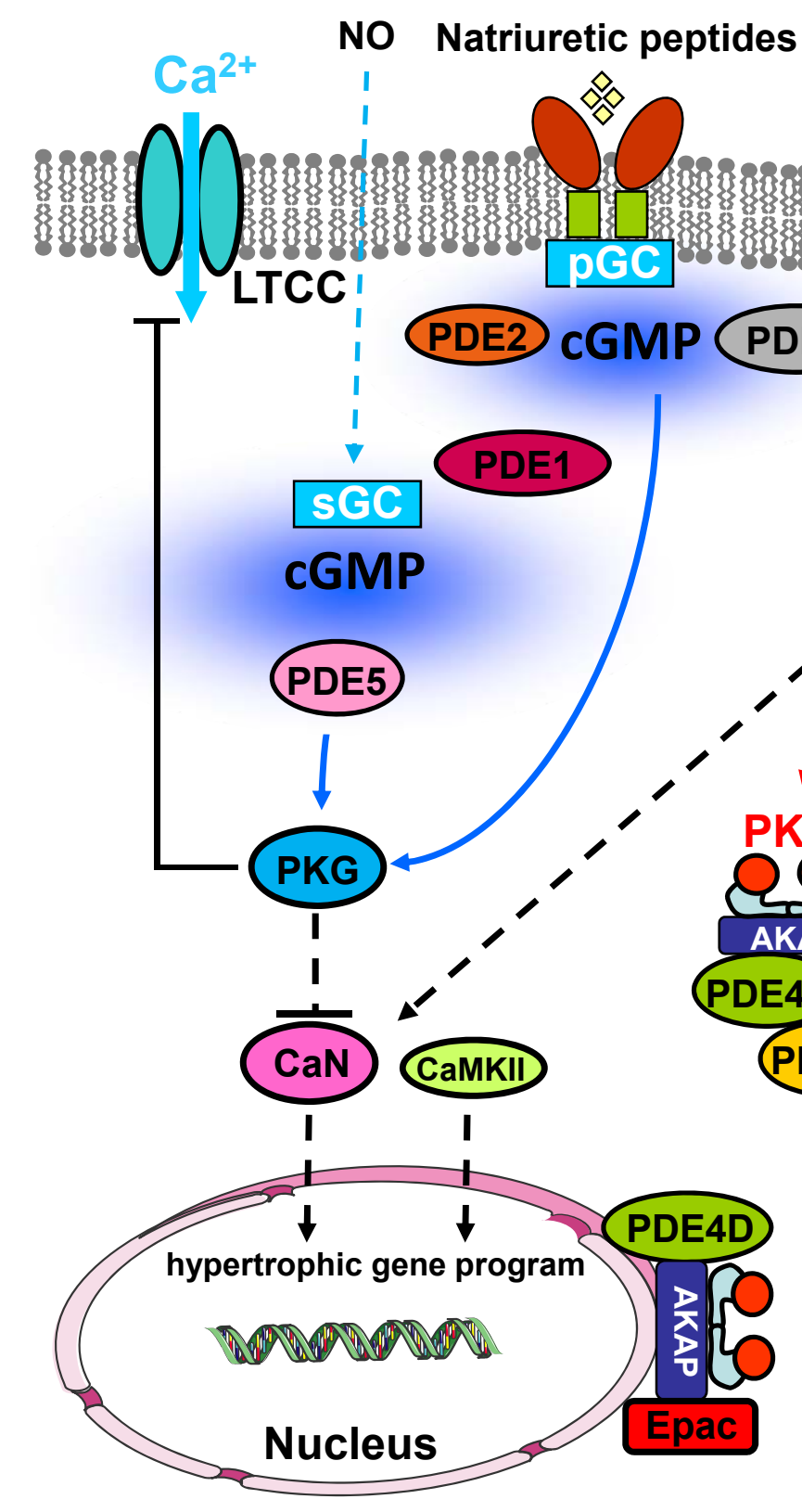

Hypertrophy
Catecholamines

out

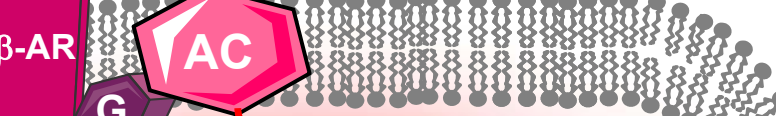$$
\text { , }
$$
CAMP

\section{}

\section{Contraction}

Figure 1 


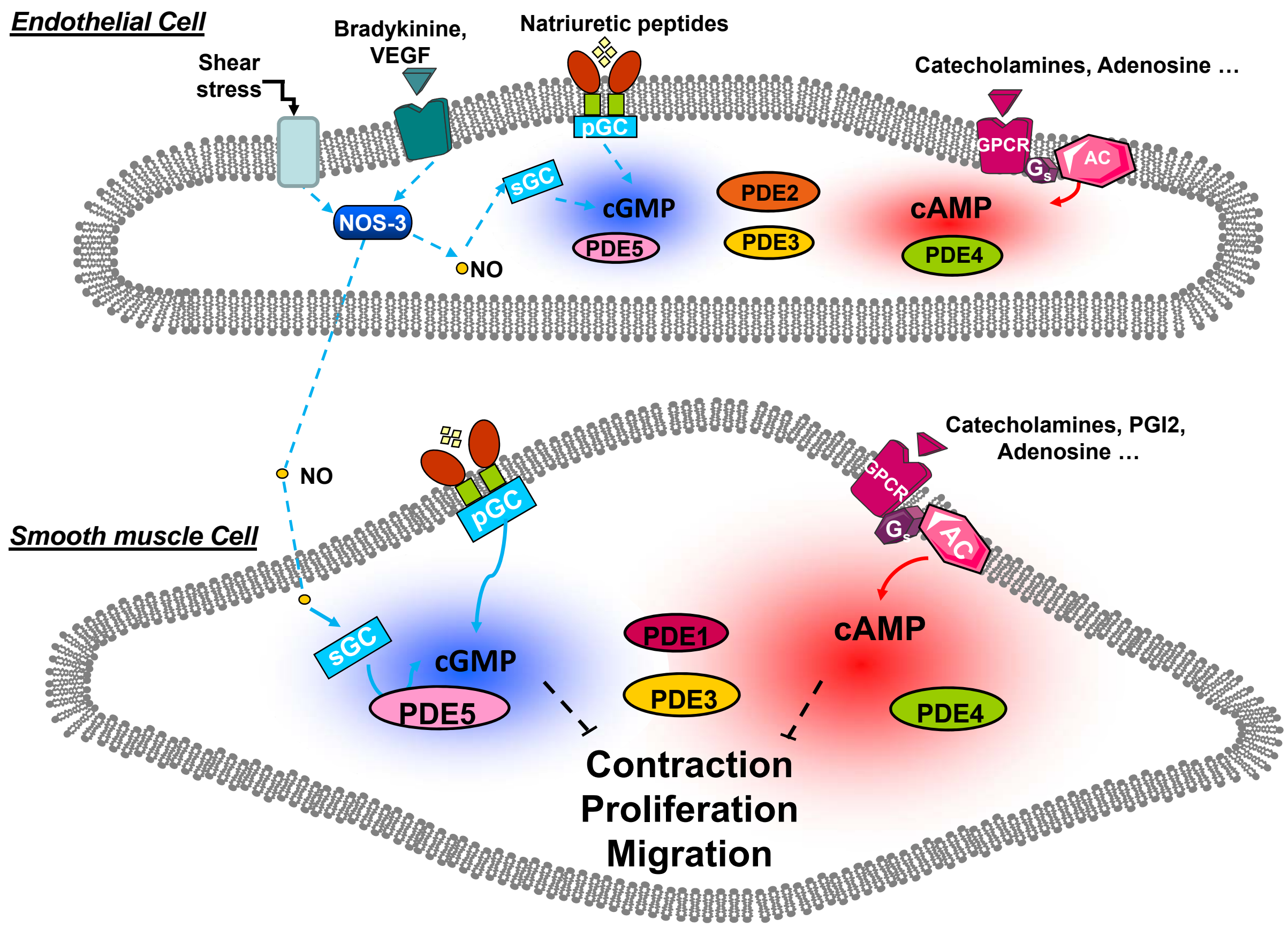

Figure 2 